\title{
BMJ Open Association of ACE gene D polymorphism with left ventricular hypertrophy in patients with diastolic heart failure: a case-control study
}

\author{
Ehsan Bahramali, ${ }^{1,2}$ Mona Rajabi, ${ }^{1}$ Javad Jamshidi, ${ }^{1,3}$ Seyyed Mohammad Mousavi, ${ }^{1}$ \\ Mehrdad Zarghami, ${ }^{1}$ Alireza Manafi, ${ }^{1}$ Negar Firouzabadi ${ }^{4}$
}

To cite: Bahramali E,

Rajabi M, Jamshidi J, et al. Association of ACE gene D polymorphism with left ventricular hypertrophy in patients with diastolic heart failure: a case-control study. BMJ Open 2016;6:e010282. doi:10.1136/bmjopen-2015010282

- Prepublication history and additional material is available. To view please visit the journal (http://dx.doi.org/ 10.1136/bmjopen-2015010282)

Received 17 October 2015 Revised 16 December 2015 Accepted 14 January 2016

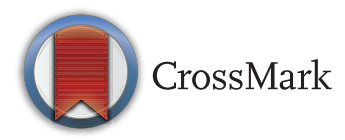

${ }^{1}$ Noncommunicable Diseases Research Center, Fasa University of Medical Sciences, Fasa, Iran ${ }^{2}$ Cardiology Departments, Fasa University of Medical Sciences, Fasa, Iran ${ }^{3}$ Medical Genetics Department, Fasa University of Medical Sciences, Fasa, Iran

${ }^{4}$ Pharmacology and Toxicology Department, School of Pharmacy, Shiraz University of Medical Sciences, Shiraz, Iran

Correspondence to Dr Ehsan Bahramali; ebahramali@fums.ac.ir

\section{ABSTRACT}

Objectives: To explore the association between ACE gene insertion/deletion (I/D) polymorphism with left ventricular hypertrophy (LVH) in patients with hypertension who have developed heart failure with preserved ejection fraction (HFpEF). Being a major contributor to the development of diastolic heart dysfunction, the renin angiotensin aldosterone system and its genetic variations are thought to induce LVH in hypertensive hearts apart from haemodynamic factors.

Design: Case control study.

Setting: An Iranian referral university hospital.

Participants: 176 patients with hypertension and a diagnosis of $\mathrm{HFpEF}$ on presence of symptoms of heart failure plus Doppler echocardiographic documentation of left ventricular (LV) diastolic dysfunction and/or elevated NT-proBNP levels. Those with significant coronary, valvular, pericardial and structural heart diseases were excluded as well as patients with atrial fibrillation, renal failure and pulmonary causes of dyspnoea. They were divided into two cohorts of 88 cases with and 88 controls without LVH, after determination of LV mass index, using twodimensional and M-mode echocardiography. The I/D polymorphism of the $A C E$ gene was determined using the PCR method.

Results: The $D$ allele was significantly more prevalent among cases with compared with controls without LVH $(p=0.0007)$. Genotype distributions also differed significantly under additive $(\mathrm{p}=0.005, \mathrm{O}=0.53,95 \%$ $\mathrm{Cl} 0.34$ to 0.84 ) and recessive ( $p=0.001,0 R=0.29$, $95 \% \mathrm{Cl} 0.13$ to 0.66 ) models.

Conclusions: In patients with hypertension who develop HFpEF, the $\mathrm{D}$ allele of the $A C E$ gene is probably associated with the development of LVH. With the detrimental effects of LVH on the heart's diastolic properties, this can signify the role of genetic contributors to the development of HFpEF in patients with hypertension and may serve as a future risk predictor for the disease.

\section{INTRODUCTION}

Hypertension is one of the most important risk factors of atherosclerotic diseases. ${ }^{1}$ It is

\section{Strengths and limitations of this study}

- In this study, we genotyped ACE insertion/deletion polymorphism in 176 patients with hypertension who had developed heart failure with preserved ejection fraction (HFpEF).

- This study made comparison of genotype distribution between cases with and controls without left ventricular hypertrophy for the first time in a population of patients with HFpEF.

- The study included women as well as men, however, women outnumbered men partly because HFpEF is more prevalent among women.

- A diagnosis of HFpEF was made on robust criteria with measurements of left ventricular diastolic properties carried out using echocardiography, and NT-proBNP levels. The study could thus recruit 176 patients fulfilling the diagnostic criteria.

shown to be associated with the development of heart failure with preserved ejection fraction (HFpEF), a syndrome of heart failure (HF) with evidence of abnormal left ventricular (LV) diastolic function. Formerly known as diastolic HF (DHF), it represents about $50 \%$ of patients diagnosed with HF and carries morbidity and mortality risk as high as those associated with $\mathrm{HF}$ and reduced ejection fraction. ${ }^{2}$ At 5 years, the cumulative mortality rate is reported to be $65 \%$ for patients with HFpEF with an adjusted HR of 1.48 when compared with persons with no $\mathrm{HF}$ and a normal LV ejection fraction (LVEF). Besides being associated with a high incidence of systemic hypertension (70-88\%), HFpEF is highly prevalent in older and obese patients and in females. ${ }^{3}$

The diastolic function of the human heart is closely related to haemodynamic and humoral factors. Neurohormonal alterations underlying the development and progression 
of hypertension can thus have significant impact on myocardial active relaxation and passive stiffness, the pathophysiological underpinnings of elevated diastolic pressure and abnormal diastolic function. ${ }^{45}$ The renin angiotensin aldosterone system (RAS) is one of the key players. Angiotensin II, as the major effector of RAS, exerts powerful vasoconstrictor and trophic effects, and is shown to be involved in mediating deleterious consequences of hypertension. ${ }^{6}$ It is known to participate in profibrotic mechanisms by influencing extracellular matrix composition through attenuating the expression of matrix metalloproteinases (MMPs), enhancing the endogenous tissue inhibitor of MMP-1 and inducing expression of connective tissue growth factor. ${ }^{78}$ It can also stimulate myocyte hypertrophy via paracrine release of transforming growth factor and endothelin-1 from fibroblasts. ${ }^{9}$

There are several reports that genetic variations in RAS play a major role in the development of LV hypertrophy (LVH) in hypertensive hearts beyond what is expected from the chronic pressure overload alone. ${ }^{10-12}$ Insertion/deletion (I/D) polymorphism of the $A C E$ gene is the most extensively studied and has been shown to be associated with increased LV mass in both, normotensive and hypertensive populations, ${ }^{13-15}$ patients with diabetes, patients with chronic kidney disease ${ }^{16}$ and those with hypertrophic cardiomyopathy. ${ }^{17}$ While genetic determinants of $\mathrm{HFpEF}$ are not extensively studied and there is no direct report targeting genetic variations by employing genome-wide association studies (GWAS) ${ }^{18}$ genetic variants affecting neurohormonal regulation of blood pressure (BP) and associated LV mass are thus eligible candidates, knowing that LVH is considered as a critical contributor to LV diastolic dysfunction. ${ }^{4}$ Concordantly, Wu has reported that the DD genotype of the $A C E$ gene can predispose an individual to DHF in a case-control study of the Chinese population. ${ }^{19}$ Furthermore, ACE gene I/D polymorphism has been related to baseline muscular strength and power in older adults, indicating its role in overall physical performance and functional capacity, which is seriously limited in patients with HFpEF. ${ }^{20}$

In patients with a history of hypertension, with detrimental effects of increased LV mass on myocardial stiffness and diastolic heart filling, genetic determinants of RAS function might play a role in progression to HFpEF through development of LVH. This prompted us to test the hypothesis that the $\mathrm{D}$ allele of the $A C E$ gene is associated with an increased LV mass in patients with hypertension with DHF.

\section{MATERIALS AND METHODS}

Study design, setting and participants

This was a single-centre case-control study of patients with a diagnosis of HFpEF from the cardiovascular ward and clinic of Fasa University Hospital. A total of 231 patients with hypertension with clear clinical presentations of HF and normal or near normal LV systolic function were prospectively identified. A single cardiologist examined all the patients and non-invasive assessment of LV dysfunction during diastole was performed. A diagnosis of HFpEF was made based on the criteria described elsewhere, after ruling out other noncardiac causes of HF symptoms. ${ }^{21}$ Doppler and tissue Doppler echocardiography was used to measure mitral inflow early rapid filling wave (E) and mitral annular early diastolic $\left(\mathrm{E}^{\prime}\right)$ velocities, respectively. In cases with $\mathrm{E} / \mathrm{E}^{\prime}>15$, the diagnosis of $\mathrm{HFpEF}$ was made regardless of NT-proBNP levels. For those with $8<\mathrm{E} / \mathrm{E}^{\prime}<15$, NT-proBNP level of more than $220 \mathrm{pg} / \mathrm{mL}$ was used to make the diagnosis. Those with a medical history of significant coronary artery disease (CAD; 18 men, 4 women), myocardial infarction (MI; 2 men), significant valvular disease (1 man), secondary hypertension (1 man), hepatic and renal impairment (4 men, 2 women), and atrial fibrillation (9 men, 14 women), were excluded because of impact on the study variables. Finally, 176 patients were selected and divided into two groups: cases with $\mathrm{LVH}$ defined as LV mass index (LVMI) $>115 \mathrm{~g} / \mathrm{m}^{2}$ for men and LVMI $>95 \mathrm{~g} / \mathrm{m}^{2}$ for women, and risk factor-matched control group without $\mathrm{LVH}^{22}$ Demographic data and medical history were recorded at the time of echocardiography, and laboratory data were collected from their medical chart records.

\section{Echocardiography}

Measurements of LV end diastolic diameter, LV end systolic diameter, LV septal and LV posterior wall thickness, and left atrial diameter at end diastole were carried out in M-mode parasternal long axis view. Image acquisition was repeated three times and an average was calculated. In cases with suboptimal M-mode acquisition, measurements in two-dimensional views were obtained instead. Measurements of ventricular $\mathrm{E}$ wave, peak velocity of late filling wave (A), E/A, E wave deceleration time and mitral annular early diastolic velocity were carried out according to American Society of Echocardiography guidelines ${ }^{23}$ with the use of a 1-5 MHz PA transthoracic echocardiography probe, Kontron. LVMI was calculated using the Devereux $e t a t^{22}$ formulae. LVEF was estimated by an eyeballing method, and Doppler and colour Doppler studies identified patients with at least moderate aortic or mitral stenosis/regurgitation as significant valvular diseases.

\section{DNA extraction and genotyping}

After obtaining informed consent, 3-4 mL of venous blood samples of all selected patients were collected in (EDTA) containing tubes.

Genomic DNA was extracted using a salting-out method. Obtained DNA was dissolved in TE $(10 \mathrm{mM}$ Tris, $1 \mathrm{mM}$ EDTA, $\mathrm{PH}=8$ ) and stored at $-20^{\circ} \mathrm{C}$ until PCR analysis. Detection of ACE I/D polymorphism was carried out using a PCR method described 
previously. ${ }^{24}$ The primers were as follows: forward 5'-CTGGAGACCACTCCCATCCTTTCT-3' and reverse 5'-GATGTGGCCATCACATTCGTCAGAT- ${ }^{\prime}$. The PCR reaction was carried out in a total volume of $25 \mu \mathrm{L}$ containing $50-200 \mathrm{ng}$ of template DNA, $10 \mu \mathrm{M}$ of each primer, $2.5 \mu \mathrm{L}$ 10X PCR buffer (Gene Fanavaran, Iran), $2 \mathrm{mM} \mathrm{MgCl2}, 200 \mu \mathrm{M}$ each dNTP and 0.5 units of Taq DNA polymerase (Gene Fanavaran, Iran). The PCR profiles were as follows: initial denaturation at $94^{\circ} \mathrm{C}$ for $5 \mathrm{~min}$ and then 35 cycles of denaturation at $94^{\circ} \mathrm{C}$ for $40 \mathrm{~s}$, annealing at $60^{\circ} \mathrm{C}$ for $60 \mathrm{~s}$ and extension at $72^{\circ} \mathrm{C}$ for $60 \mathrm{~s}$ followed by a final elongation at $72^{\circ} \mathrm{C}$ for $5 \mathrm{~min}$. In order to avoid mistyping ID as DD genotype, each sample found to have the DD genotype was reconfirmed by another PCR with insertion-specific primers (forward $5^{\prime}$-TGGGACCACAGCGCCCGCCACTAC-3' ${ }^{\prime}$ and reverse $5^{\prime}$-TCGCCAGCCCTCCCATGCCCATAA-3') as previously described. ${ }^{25}$

\section{Statistical analysis}

All continuous variables are presented as means $\pm \mathrm{SD}$, and differences between groups were determined using Student $t$ test. Pearson's $\chi^{2}$ tests were applied to test for significance in differences of genotype and allele frequencies between the two groups. A $\mathrm{p}$ value of $<0.05$ (two tailed) was considered to be significant. The Hardy-Weinberg equilibrium was performed using Fisher's exact test. We also analysed the distribution of genotype frequencies under three different genetic models (additive $(\mathrm{D} / \mathrm{D}=0, \mathrm{I} / \mathrm{D}=1$ and $\mathrm{I} / \mathrm{I}=2)$, recessive (I/D and $\mathrm{D} / \mathrm{D}$ vs $\mathrm{I} / \mathrm{I}$ ) and dominant (I/I and $\mathrm{I} / \mathrm{D}$ vs $\mathrm{D} / \mathrm{D})$ ), using the SNPassoc package of $\mathrm{R}$ V.3.0.1. (http://www.Rproject.org). ${ }^{26}$ All other data were also analysed using R V.3.0.1.

\section{RESULTS}

A total of 176 patients were included. Eighty-eight individuals with LVH and 88 without LVH. Demographic and laboratory data of participants in case and control groups are listed in table 1 . There were no significant differences in age, body mass index (BMI), systolic and diastolic BP, diabetes mellitus status, smoking status, serum creatinine, low-density lipoprotein, high-density lipoprotein and total cholesterol levels between cases and controls. Demographic and laboratory data are also presented according to each genotype (see online supplementary table S1). Eighty-three per cent of patients with LVH were woman, compared with $58 \%$ of those without LVH $(p<0.001)$. Patients with LVH had lower haemoglobin $(12.7 \pm 1.5$ vs $13.3 \pm 1.6, \mathrm{p}=0.03)$ and higher fasting blood sugar $(145.3 \pm 64.1$ vs $127.5 \pm 68, \mathrm{p}=0.07)$ levels compared with those without LVH. Echocardiography data are shown in table 2. Genotype distribution and allele frequencies differ significantly between the two groups $(\mathrm{p}=0.0007)$, where the $\mathrm{D}$ allele was found to be more prevalent among patients with LVH (table 3). The genotype difference between groups was significant under additive $(p=0.005, O R=0.53,95 \%$ CI 0.34 to 0.84 ) and recessive ( $\mathrm{p}=0.001, \mathrm{OR}=0.29,95 \%$ CI 0.13 to 0.66 ) models (table 4). Allele frequencies were still significantly different between the two groups after adjustment for age, sex, BMI, and systolic and diastolic BP (table 3).

\section{DISCUSSION}

With the shortage of available evidence on the potential contributors to HFpEF, we postulated that genetic factors might impose greater risk of diastolic heart dysfunction in patients with hypertension by mediating development of LVH. In the present study, we showed that the $\mathrm{D}$ allele of the $A C E$ gene is associated with an increased LV mass in an Iranian population with hypertension and a diagnosis of HFpEF.

To the best of our knowledge, our report is the first to show an association between a genetic polymorphism and $\mathrm{LVH}$ in a patient population with a diagnosis of

Table 1 Demographic and laboratory data

\begin{tabular}{|c|c|c|c|c|}
\hline Variable & All $(\mathrm{N}=176)$ & Without LVH $(\mathrm{N}=88)$ & With LVH $(\mathrm{N}=88)$ & p Value \\
\hline Age & $62.5 \pm 12.6$ & $61.70 \pm 13.26$ & $63.3 \pm 12.01$ & 0.35 \\
\hline BMI $\left(\mathrm{kg} / \mathrm{m}^{2}\right)$ & $26.41 \pm 5.47$ & $26.78 \pm 5.52$ & $26.04 \pm 5.43$ & 0.37 \\
\hline $\operatorname{Sex}(F / M)$ & $124 / 52$ & $51 / 37$ & $73 / 15$ & $<0.001$ \\
\hline Smoking (\%) & 13.5 & 14 & 13 & 0.82 \\
\hline $\mathrm{DM}(\%)$ & 35 & 30 & 40 & 0.15 \\
\hline $\mathrm{SBP}(\mathrm{mm} \mathrm{Hg})$ & $143.2 \pm 27.2$ & $141.2 \pm 26.9$ & $145.3 \pm 27.4$ & 0.32 \\
\hline $\mathrm{DBP}(\mathrm{mm} \mathrm{Hg})$ & $84.5 \pm 11.4$ & $84.5 \pm 12.4$ & $84.4 \pm 10.5$ & 0.97 \\
\hline $\mathrm{HB}(\mathrm{g} / \mathrm{dL})$ & $13.0 \pm 1.6$ & $13.3 \pm 1.6$ & $12.7 \pm 1.5$ & 0.03 \\
\hline $\mathrm{Cr}(\mathrm{mg} / \mathrm{dL})$ & $1.12 \pm 0.33$ & $1.09 \pm 0.30$ & $1.16 \pm 0.35$ & 0.20 \\
\hline FBS (mg/dL) & $136.4 \pm 66.4$ & $127.5 \pm 68$ & $145.3 \pm 64.1$ & 0.07 \\
\hline $\mathrm{TG}(\mathrm{mg} / \mathrm{dL})$ & $163.7 \pm 85.2$ & $166.6 \pm 99.3$ & $160.8 \pm 68.7$ & 0.65 \\
\hline LDL (mg/dL) & $114.9 \pm 32.8$ & $112.9 \pm 33.4$ & $117.0 \pm 32.3$ & 0.40 \\
\hline $\mathrm{HDL}(\mathrm{mg} / \mathrm{dL})$ & $39.9 \pm 8.8$ & $39.9 \pm 8.9$ & $39.9 \pm 8.7$ & 0.97 \\
\hline
\end{tabular}


Table 2 Echocardiography data

\begin{tabular}{|c|c|c|c|c|}
\hline & All $(\mathrm{N}=176)$ & Without LVH $(\mathrm{N}=88)$ & With LVH (N=88) & p Value \\
\hline IVS (cm) & $1.21 \pm 0.17$ & $1.13 \pm 0.17$ & $1.29 \pm 0.14$ & $<0.001$ \\
\hline LVPW (cm) & $1.19 \pm 0.17$ & $1.10 \pm 0.17$ & $1.27 \pm 0.13$ & $<0.001$ \\
\hline LVEDD (cm) & $4.18 \pm 0.67$ & $3.87 \pm 0.57$ & $4.50 \pm 0.64$ & $<0.001$ \\
\hline LVMI $\left(\mathrm{g} / \mathrm{m}^{2}\right)$ & $104.90 \pm 35.01$ & $80.34 \pm 19.05$ & $129.49 \pm 29.69$ & $<0.001$ \\
\hline LA diameter (cm) & $3.50 \pm 0.56$ & $3.38 \pm 0.61$ & $3.62 \pm 0.48$ & 0.003 \\
\hline LVEF & $0.55 \pm 0.06$ & $0.56 \pm 0.04$ & $0.55 \pm 0.08$ & 0.04 \\
\hline$E(m / s)$ & $0.64 \pm 0.21$ & $0.62 \pm 0.18$ & $0.67 \pm 0.24$ & 0.20 \\
\hline$A(\mathrm{~m} / \mathrm{s})$ & $0.85 \pm 0.21$ & $0.85 \pm 0.17$ & $0.86 \pm 0.25$ & 0.78 \\
\hline$E / A$ & $0.77 \pm 0.29$ & $0.74 \pm 0.21$ & $0.81 \pm 0.35$ & 0.17 \\
\hline $\mathrm{Sm}(\mathrm{cm} / \mathrm{s})$ & $7.41 \pm 2.01$ & $7.72 \pm 2.05$ & $7.11 \pm 1.95$ & 0.045 \\
\hline $\mathrm{E}^{\prime}(\mathrm{cm} / \mathrm{s})$ & $6.61 \pm 1.46$ & $6.77 \pm 1.43$ & $6.47 \pm 1.48$ & 0.16 \\
\hline $\mathrm{A}^{\prime}(\mathrm{cm} / \mathrm{s})$ & $10.10 \pm 2.16$ & $10.26 \pm 1.97$ & $10.21 \pm 1.98$ & 0.30 \\
\hline$E / E^{\prime}$ & $10.18 \pm 3.79$ & $9.53 \pm 3.01$ & $10.83 \pm 4.37$ & 0.024 \\
\hline DT (ms) & $184.7 \pm 63.07$ & $191.81 \pm 58.18$ & $177.60 \pm 67.20$ & 0.13 \\
\hline
\end{tabular}

$A$, peak velocity of late filling wave; $A^{\prime}$, mitral annular late diastolic velocity; $D T$, deceleration time; $E$, mitral inflow early diastolic velocity; $E^{\prime}$, mitral annular early diastolic velocity; IVS, interventricular septum; LA, left atrium; LVEDD, left ventricular end diastolic diameter; LVEF, left ventricular ejection fraction; LVH, left ventricular hypertrophy; LVMI, left ventricular mass index; LVPW, left ventricular posterior wall diameter; Sm, systolic mitral annular velocity.

HFpEF. Studies targeting genetic contributors of DHF are scarce. While genes contributing to DHF risk in humans still await identification, ${ }^{27}$ our results may exemplify one such attempt and corroborate the role of genetic factors in susceptibility of hypertensive hearts to develop HFpEF. However, one limitation of this study is that $70 \%$ of participants are women. Although HFpEF is more prevalent among women, ${ }^{2}$ there is no epidemiological study reporting the female-to-male ratio of Iranian patients with HFpEF. Therefore, future studies targeting men with hypertension with HFpEF is warranted. Furthermore, as this was a case-control study, determination of the exact duration of hypertension in the patients was not feasible. Although it was their first documentation of HFpEF and symptom presentation, these patients likely has hypertension undiagnosed or untreated over a longer time period. This problem needs to be addressed in a cohort study of healthy individuals without hypertension, with frequent and long enough follow-ups to detect the development of hypertension and consequent HFpEF.

As one of the end organ damages associated with hypertension, LVH identifies with a poor outcome and strongly predicts MI, stroke and cardiovascular death in patients with hypertension. ${ }^{28}$ Mohammed et $a l^{29}$ studied autopsy findings and reported that patients with HFpEF have more cardiac hypertrophy, coronary microvascular rarefaction and fibrosis compared with age-matched controls. The observed increased incidence of HFpEF in patients with hypertension is related to $\mathrm{LVH}$ and only adequate control of BP reduces progression from hypertension to $\mathrm{HF}^{30}$ Antihypertensive medications are shown to reduce LV chamber stiffness along with cardiac hypertrophy, which eventually leads to improved LV diastolic filling. ${ }^{28} 3132$

An increased LV mass, a common finding in patients with diastolic dysfunction, ${ }^{4}{ }^{29}$ is a consequence of prolonged pressure overload in patients with hypertension, however, neurohormonal alterations and genetic determinants are also known to be involved. ${ }^{33} 34$ Activation of RAS as a major contributor to the pathophysiology of hypertension leads to vasoconstriction and sodium and fluid retention. ${ }^{3}$ Angiotensin II, the end product of RAS, has trophic influences on cardiomyocytes ${ }^{35}$ and increases collagen synthesis as well by means of activating metalloproteases. ${ }^{36}$ In an animal model of DHF, Yamamoto $e t a l^{37}$ found that RAS contributes to the transition to DHF through the development of excessive hypertrophy and ventricular fibrosis in hypertensive heart disease. Intracrine mechanisms for Ag II are also

Table 3 Distribution of genotypes and allele frequencies between patients with and without LVH

\section{Genotype frequencies (\%)}

\begin{tabular}{lrllllllll} 
Patients & I/I & I/D & D/D & p Value & $\begin{array}{l}\text { Adjusted } \\
\text { p value* }\end{array}$ & I & D & p Value & $\begin{array}{l}\text { Adjusted } \\
\text { p value }\end{array}$ \\
\hline With LVH & $9(12.3)$ & $50(59)$ & $29(28.7)$ & $0.007 \dagger$ & $0.004 \dagger$ & $68(38.6)$ & $108(61.4)$ & $0.007 \dagger$ & 0.016 \\
Without & $25(35.2)$ & $43(38.9)$ & $20(25.9)$ & & & $93(52)$ & $83(47)$ & & \\
LVH & & & & & & & & \\
\hline
\end{tabular}


Table 4 Analysis of genotype distributions under three genetic models

\begin{tabular}{|c|c|c|c|}
\hline & Additive $_{(\mathrm{D} / \mathrm{D}=0, \mathrm{l} / \mathrm{D}=1 \text { and } \mathrm{l} / \mathrm{l}=2)}$ & Recessive (I/D and D/D vs I/I) & Dominant (I/I and I/D vs D/D) \\
\hline $\mathrm{p}$ Value & $0.005^{\star}$ & $0.001^{*}$ & 0.12 \\
\hline OR & 0.53 & 0.29 & 0.60 \\
\hline $95 \% \mathrm{Cl}$ & 0.34 to 0.84 & 0.13 to 0.66 & 0.31 to 1.17 \\
\hline Adjusted $p$ value $†$ & $0.012^{*}$ & $0.002^{*}$ & 0.34 \\
\hline
\end{tabular}

described. Baker et al showed that intracellular expression of Ag II peptide leads to hypertrophic growth of rat cardiomyocytes without an increase in BP or in serum Ag II levels. The resulting hypertrophy and fibrosis associated with Ag II action then produces a non-compliant LV chamber with diminished ability of active relaxation, which is thought to be the pathophysiological underpinning of DHF. ${ }^{38}$

Among genetic polymorphisms of different components of RAS, I/D polymorphism of the ACE gene is the most extensively studied and is shown to be associated with CAD, MI, stroke and depression. We have previously, in the Iranian population, shown that the $\mathrm{D}$ allele is also associated with CAD in depressed patients. ${ }^{39}$ The observed association of the $\mathrm{D}$ allele of the $A C E$ gene with LVH in patients with hypertension with HFpEF in this study suggests the role of genetic factors in inducing hypertrophy and diastolic dysfunction. Previous reports have suggested the role of the $\mathrm{D}$ allele in the development of LVH in patients with hypertension. Gharavi et $a l^{11}$ demonstrated that the $\mathrm{D}$ allele of the $A C E$ gene, independently of other covariates, is associated with cardiac mass and relative wall thickness in patients with hypertension. Concordantly, Celentano et al $\mathrm{l}^{4}$ concluded that the DD genotype is a genetic marker of LVH in systemic hypertension. However, there is conflicting evidence as well debating the association of the $\mathrm{D}$ allele with LVH in a large Framingham study population, and in Chinese patients with hypertension. ${ }^{12} 40$

Being under the influence of genetic determinants, RAS activation may lead to cardiac hypertrophy and the resulting increased LV mass can be viewed as a marker of progression to HFpEF in patients with hypertension. Besides, there are reports that older adult carriers of the D allele of the ACE gene have a greater physical performance level in a 6 min walk test compared with those with a II genotype. ${ }^{20}$ This is consistent with our findings and implicates the muscular hypertrophic role of the $\mathrm{D}$ allele in augmenting muscular mass in adults alongside inducing cardiac hypertrophy. It may have implications in clinical assessment of HFpEF and affect the severity of symptoms; an issue that needs to be addressed in future studies.

\section{CONCLUSION}

The observed increased likelihood of LVH in carriers of the D allele with hypertension and HFpEF in our study strengthens the proposition that inheritance of the $\mathrm{D}$ allele can increase the risk of developing HFpEF in patients with hypertension. Such genetic determinants could potentially have important therapeutic indications as well as risk stratifying capabilities in future.

Acknowledgements The authors would like to thank Fasa NCD Research Center staff who helped them in finding the cases alongside the process of Fasa Registry of Systolic Heart Failure (FaRSH) enrolment.

Contributors EB designed the study, performed all the echocardiographic examinations, was involved with data interpretation and supervised the analysis, and wrote and made the final review of the manuscript. MR performed the laboratory work and PCR, and was involved with data interpretation. JJ was involved with the study design, set up the PCR and laboratory work, carried out the interpretation and analysis, and helped in writing the manuscript's methods section. SMM, MZ and AM assisted with clinical data gathering, laboratory work and PCR. NF was involved with the study design, and assisted with analysis and in writing the manuscript.

Funding This study was funded by a general research grant from Fasa University of Medical Sciences (grant number 92010).

Competing interests None declared.

Patient consent Obtained.

Ethics approval This study was approved by the ethics committee of Fasa University of Medical Sciences.

Provenance and peer review Not commissioned; externally peer reviewed.

Data sharing statement No additional data are available.

Open Access This is an Open Access article distributed in accordance with the Creative Commons Attribution Non Commercial (CC BY-NC 4.0) license, which permits others to distribute, remix, adapt, build upon this work noncommercially, and license their derivative works on different terms, provided the original work is properly cited and the use is non-commercial. See: http:// creativecommons.org/licenses/by-nc/4.0/

\section{REFERENCES}

1. Kannel WB. Blood pressure as a cardiovascular risk factor: prevention and treatment. JAMA 1996;275:1571-6.

2. Smiseth OA, Opdahl A, Boe E, et al. Heart failure with preserved ejection fraction-a review. European Cardiol 2012;8:186-91.

3. Garg N, Senthilkumar A, Nusair MB, et al. Heart failure with a normal left ventricular ejection fraction: epidemiology, pathophysiology, diagnosis and management. Am J Med Sci 2013;346:129-36.

4. Verma A, Solomon SD. Diastolic dysfunction as a link between hypertension and heart failure. Med Clin North Am 2009;93: 647-64.

5. Zile MR, Baicu CF, Gaasch WH. Diastolic heart failureabnormalities in active relaxation and passive stiffness of the left ventricle. N Engl J Med 2004;350:1953-9.

6. Duprez DA. Role of the renin-angiotensin-aldosterone system in vascular remodeling and inflammation: a clinical review. J Hypertens 2006;24:983-91. 
7. Castoldi G, Di Gioia CR, Pieruzzi F, et al. ANG II increases TIMP-1 expression in rat aortic smooth muscle cells in vivo. Am J Physiol Heart Circ Physiol 2003;284:H635-43.

8. Rupérez M, Lorenzo Ó, Blanco-Colio LM, et al. Connective tissue growth factor is a mediator of angiotensin II-induced fibrosis. Circulation 2003;108:1499-505.

9. Gray MO, Long CS, Kalinyak JE, et al. Angiotensin II stimulates cardiac myocyte hypertrophy via paracrine release of TGF- $\beta 1$ and endothelin-1 from fibroblasts. Cardiovasc Res 1998; 40:352-63.

10. Perticone F, Ceravolo R, Cosco C, et al. Deletion polymorphism of angiotensin-converting enzyme gene and left ventricular hypertrophy in southern Italian patients. J Am Coll Cardiol 1997;29:365-9.

11. Gharavi AG, Lipkowitz MS, Diamond JA, et al. Deletion polymorphism of the angiotensin-converting enzyme gene is independently associated with left ventricular mass and geometric remodeling in systemic hypertension. Am J Cardiol 1996;77:1315-19.

12. Jeng JR. Carotid thickening, cardiac hypertrophy, and angiotensin converting enzyme gene polymorphism in patients with hypertension. Am J Hypertens 2000;13(1 Pt 1):111-19.

13. Linhart A, Sedláček K, Jachymova M, et al. Lack of association of angiotensin-converting enzyme and angiotensinogen genes polymorphisms with left ventricular structure in young normotensive men. Blood Press 2000;9:47-51.

14. Celentano A, Mancini FP, Crivaro M, et al. Cardiovascular risk factors, angiotensin-converting enzyme gene I/D polymorphism, and left ventricular mass in systemic hypertension. Am J Cardiol 1999;83:1196-200.

15. Osono E, Kurihara S, Hayama N, et al. Insertion/deletion polymorphism in intron 16 of the ACE gene and left ventricular hypertrophy in patients with end-stage renal disease. Am J Kidney Dis 1998;32:725-30.

16. Estacio RO, Jeffers BW, Havranek EP, et al. Deletion polymorphism of the angiotensin converting enzyme gene is associated with an increase in left ventricular mass in men with type 2 diabetes mellitus. Am J Hypertens 1999;12:637-42.

17. Doolan G, Nguyen L, Chung J, et al. Progression of left ventricular hypertrophy and the angiotensin-converting enzyme gene polymorphism in hypertrophic cardiomyopathy. Int $J$ Cardiol 2004;96:157-63.

18. Deng AY. Genetics of diastolic heart failure. J Hypertens 2013;31:2329-36.

19. Wu CK, Tsai CT, Hwang JJ, et al. Renin-angiotensin system gene polymorphisms and diastolic heart failure. Eur J Clin Invest 2008;38:789-97.

20. Keogh JW, Palmer BR, Taylor D, et al. ACE and UCP2 gene polymorphisms and their association with baseline and exercise-related changes in the functional performance of older adults. PeerJ 2015;3:e980

21. Paulus WJ, Tschöpe C, Sanderson JE, et al. How to diagnose diastolic heart failure: a consensus statement on the diagnosis of heart failure with normal left ventricular ejection fraction by the Heart Failure and Echocardiography Associations of the European Society of Cardiology. Eur Heart J 2007;28:2539-50.

22. Devereux RB, Alonso DR, Lutas EM, et al. Echocardiographic assessment of left ventricular hypertrophy: comparison to necropsy findings. Am J Cardiol 1986;57:450-8.

23. Quiñones MA, Otto CM, Stoddard M, et al. Recommendations for quantification of Doppler echocardiography: a report from the Doppler Quantification Task Force of the Nomenclature and
Standards Committee of the American Society of Echocardiography. $J$ Am Soc Echocardiogr 2002;15:167-84.

24. Rigat B, Hubert C, Corvol P, et al. PCR detection of the insertion/ deletion polymorphism of the human angiotensin converting enzyme gene (DCP1) (dipeptidyl carboxypeptidase 1). Nucleic Acids Res 1992;20:1433.

25. Shanmugam V, Sell KW, Saha BK. Mistyping ACE heterozygotes. PCR Methods Appl 1993;3:120-1.

26. González JR, Armengol L, Solé X, et al. SNPassoc: an R package to perform whole genome association studies. Bioinformatics 2007;23:644-5.

27. Schocken DD, Benjamin EJ, Fonarow GC, et al. Prevention of heart failure: a scientific statement from the American Heart Association Councils on Epidemiology and Prevention, Clinical Cardiology, Cardiovascular Nursing, and High Blood Pressure Research; Quality of Care and Outcomes Research Interdisciplinary Working Group; and Functional Genomics and Translational Biology Interdisciplinary Working Group. Circulation 2008;117:2544-65.

28. Devereux RB, Dahlöf B, Gerdts E, et al. Regression of hypertensive left ventricular hypertrophy by losartan compared with atenolol: the Losartan Intervention for Endpoint Reduction in Hypertension (LIFE) trial. Circulation 2004;110:1456-62.

29. Mohammed SF, Hussain S, Mirzoyev SA, et al. Coronary microvascular rarefaction and myocardial fibrosis in heart failure with preserved ejection fraction. Circulation 2015;131:550-9.

30. Gradman AH, Wilson JT. Hypertension and diastolic heart failure. Curr Cardiol Rep 2009;11:422-9.

31. Artham SM, Lavie CJ, Milani RV, et al. Clinical impact of left ventricular hypertrophy and implications for regression. Prog Cardiovasc Dis 2009;52:153-67.

32. Diez J, Querejeta R, Lopez B, et al. Losartan-dependent regression of myocardial fibrosis is associated with reduction of left ventricular chamber stiffness in hypertensive patients. Circulation 2002:105:2512-17.

33. Arnett DK. Genetic contributions to left ventricular hypertrophy. Curr Hypertens Rep 2000;2:50-5.

34. Devereux RB, Roman MJ. Left ventricular hypertrophy in hypertension: stimuli, patterns, and consequences. Hypertens Res 1999;22:1-9.

35. Baker KM, Chernin MI, Wixson SK, et al. Renin-angiotensin system involvement in pressure-overload cardiac hypertrophy in rats. $\mathrm{Am} \mathrm{J}$ Physiol 1990;259(2 Pt 2):H324-32.

36. Takaguri A, Shirai H, Kimura K, et al. Caveolin-1 negatively regulates a metalloprotease-dependent epidermal growth factor receptor transactivation by angiotensin II. J Mol Cell Cardiol 2011;50:545-51.

37. Yamamoto K, Masuyama T, Sakata Y, et al. Roles of renin-angiotensin and endothelin systems in development of diastolic heart failure in hypertensive hearts. Cardiovasc Res 2000;47:274-83.

38. Kawasaki D, Kosugi K, Waki $\mathrm{H}$, et al. Role of activated renin-angiotensin system in myocardial fibrosis and left ventricular diastolic dysfunction in diabetic patients-reversal by chronic angiotensin II type 1A receptor blockade. Circ J 2007;71:524-9.

39. Firouzabadi N, Tajik N, Bahramali E, et al. Association of angiotensin-converting enzyme polymorphism with coronary artery disease in Iranian patients with unipolar depression. Clin Biochem 2012;45:1347-52.

40. Cheung $B$. Absence of association or genetic linkage between the angiotensin-converting-enzyme gene and left ventricular mass. N Engl J Med 1996;335:1070-1. 